\title{
GRAPHICAL AND VISIBLE VISUALIZATION OF WIND FORCE EFFECT FOR BROILER HOUSE
}

\author{
Mohamed A. Basiouny ${ }^{1}$
}

\section{ABSTRACT}

TWO sets of experiments were carried out to study wind-induced natural ventilation process (wind force) through two different types of fabricated physical models namely ( $A$ and $B$ ) and simulating broiler houses inside a wind tunnel. The first set as the main experiments that used wind pressure difference method to determine and calculate wind pressure coefficients, airflow rates, and ventilation coefficients under four wind angles $\left(0.0,30,60\right.$ and $\left.90^{\circ}\right)$ and two wind velocities $(2.5$ and $3.6 \mathrm{~m} / \mathrm{s})$ for two different types of studied models differ in configurations. Graphical visualization for inlet and outlet zones were presented on the plan view of the physical model. The second set was the auxiliary experiments that implemented to visualize the inlet and outlet zones by using smoke around the models envelope. The results demonstrated that, the highest mean values of wind pressure coefficients on windward wall for models $A$ and $B$ were obtained at wind angle of $90^{\circ}$ and wind velocity of $3.6 \mathrm{~m} / \mathrm{s}$. However, the mean value of wind pressure coefficient on the windward wall for model-B was higher than that of model-A by about $63.55 \%$. Also, the maximum value of ventilation rate was $0.2134 \mathrm{~m}^{3} / \mathrm{s}$ at wind angle of $60^{\circ}$ and $3.6 \mathrm{~m} / \mathrm{s}$ wind velocity for model-B. While, the highest value of ventilation coefficient was 0.8 at $90^{\circ}$ wind angle and $2.5 \mathrm{~m} / \mathrm{s}$ wind velocity for model-B. Comparative study between the two tested physical models, showed that, model-B was found to be the most adequate for uniformity the airflow shape.

\section{INTRODUCTION}

$\mathrm{N}$ atural ventilation replaces indoor air with fresh outdoor air without using mechanical power. Hence, natural ventilation can save energy consumed by heating, ventilating, and airconditioning systems in a building if it provides acceptable indoor air quality and thermal comfort levels. In a naturally ventilated building, air

${ }^{1}$ Senior researcher in Agric. Eng. Res. Inst. (AEnRI), ARC, Giza, Egypt. 
is driven in and out due to pressure differences produced by wind or buoyancy forces. In poultry industries, ventilation system creates air velocity that has a significant influence on animal heat loss. In addition, ventilation system is used not only for the control of indoor environment and reduces gas concentration but also to achieve a suitable air velocity in the broiler house for the animal, especially in summer season (Jiang et al., 2003; Blanes-Vidal et al., 2007 and Rahman et al., 2014). In Egypt, most of common broiler houses depend on natural ventilation. Since the weather is tend to be warm or hot most of the year, wind-induced natural ventilation (wind force) is the predominant one. No more studies had been found to explain this type of natural ventilation under the common Egyptian specifications of the broiler houses (Basiouny, 2005). The qualitative study of airflow pattern is important to determine the quality of airflow distribution for designing a predictable natural ventilation system. The determination of airflow patterns is the first step towards complementing the design requirement for the successful application of natural ventilation system in livestock housing (Ismail, 2007). The main problem in wind induction natural ventilation behavior of a broiler house under different orientation in relation to wind direction, different wind velocities and some building configurations is so difficult to be studied in the field. Physical models and a unit to control air direction and velocity (wind tunnel) offer a good methodology to accomplish such task. Therefore, the aim of this study was to introduce graphical and visible visualization of wind force effect for inlet and outlet zones around the physical models of broiler houses inside a wind tunnel.

\section{MATERIALS AND METHODS}

Two sets of experiments were carried out to study wind forces effect through two different types of physical models of broiler houses inside a wind tunnel. These physical models represent the commercial poultry houses for meat production in Egypt. First set is the main experiments in which wind pressure around the broiler house models envelope was measured. Then, wind pressure difference method was used to determine and calculate wind pressure coefficients, airflow rates, and ventilation coefficients under different four wind angles of incidence and two wind velocities for the two different studied models. The obtained data were 
implemented to graphically visualize inlet and outlet zones around the physical model envelope. Second set is the auxiliary experiments that were implemented to show airflow movement through and around the physical models using smoke as a tracer. A visible visualization of inlet and outlet zones was then accomplished. Special regime of experiments were carried out during the year of 2015 at Rice Mechanization Center, Meet El-Deeba, Kafrelsheikh Governorate, Egypt.

\section{PHYSICAL MODEL AND WIND TUNNEL:}

A scale model was used to physically simulate the real system of the broiler housing. One of the conditions of scaling the experimental models is the geometric uniformity between the model and real building. This means that, all dimensions of the real buildings should be equally scaled. The developed scale models of the experimental work were a copy of a building with 5000-bird load, which represents most common of the broiler houses in Egypt. The model was constructed to simulate a broiler house of 50m long, 10m wide, and $3.5 \mathrm{~m}$ height. Two 1:25 scale models $\mathrm{A}$ and $\mathrm{B}$ of broiler houses were designed and built for the present study. The models have the same size while differ in configuration. Model-A was constructed without windows at the endwalls and the model-B having windows at the endwalls. The sizes of the models were $2 \mathrm{~m}$ long, $0.4 \mathrm{~m}$ wide, and $0.14 \mathrm{~m}$ height and the ceilings were a horizontal type. There are no any partitions inside both of the two models. The windows area of the model represent about $24 \%$ or $17 \%$ of the total wall or total floor area, respectively (Abdel-Ghafar, 1984). The size of the window of the models was $12 \mathrm{~cm}$ wide and $5.5 \mathrm{~cm}$ height. Total number of windows for models A and B were 24 and 28, respectively. Isometric of models A and B are shown in Fig. 1.

A wind tunnel experimental unit was developed and constructed to simulate wind forces effect. The wind tunnel is a low speed open circuit type with a test section of $2.5 \mathrm{~m}$ long, $2.5 \mathrm{~m}$ wide and $0.75 \mathrm{~m}$ height. It was constructed of welded steel angles (50x50)mm to form tunnel frame with overall length of $6.15 \mathrm{~m}$. The constructed frame of the wind tunnel was covered with a $1 \mathrm{~mm}$ thick iron sheet. A Plexiglas with $3 \mathrm{~mm}$ thick was employed to cover the iron frame to form the ceiling and walls of the test section. 


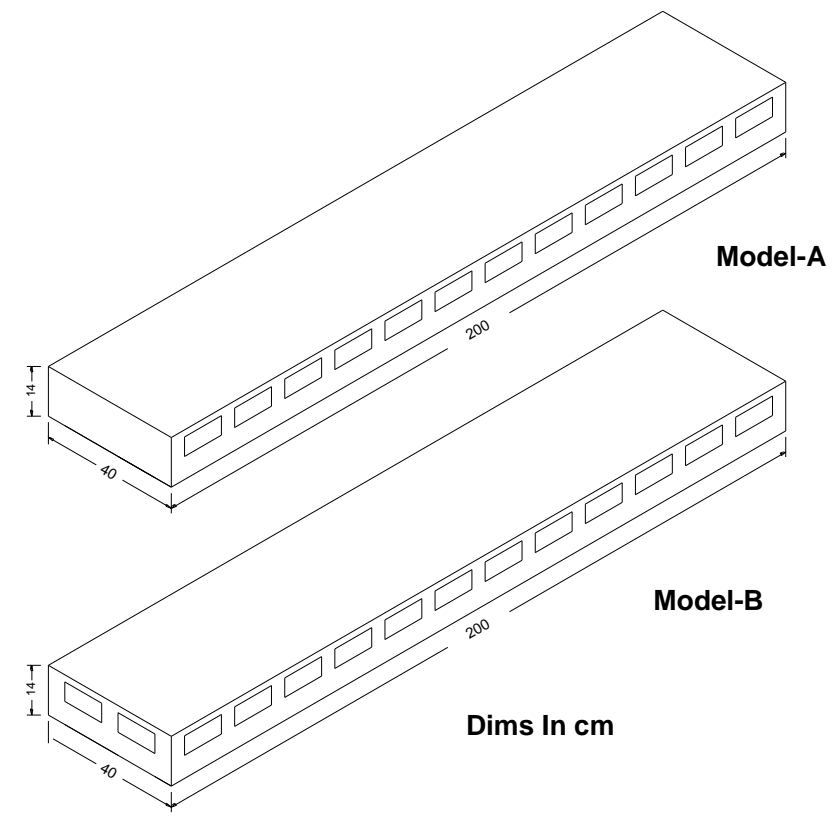

Fig. 1: Isometric of models A and B.
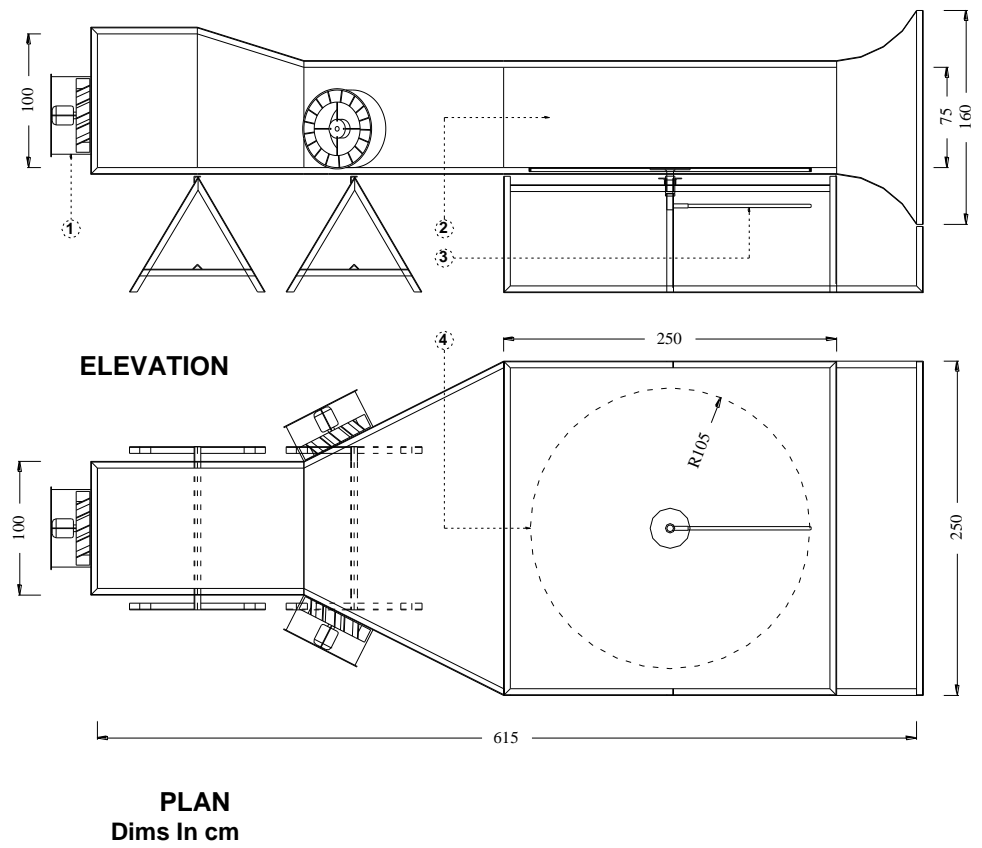

1) Axial flow fan; 2) Test section; 3) Turntable handle; 4) Turntable

Fig. 2: Elevation and plan of the wind tunnel. 
Three similar axial flow fans, attached to the frame of the wind tunnel were used to furnish air to the wind tunnel. A turntable fixed on a spindle was mounted on the floor of the test section through a shaft and two bearing to turn $360^{\circ}$. The movement and control of the turntable was attended through a manual iron shaft fixed to the spindle. The models were rested over the turntable and tested for different wind angles of incidence of the model. The rough structure of the wind tunnel are shown in Figs. 2 and 3. Construction details of the tunnel and two models can be found in Basiouny, 2005.

\section{EXPERIMENTAL TREATMENTS:}

The airflow visualization are evaluated under the following treatments:

( Two different types of configuration models namely: A (without windows at the endwalls) and B (with windows at the endwalls);

4 Two different reference wind velocities of 2.5 and $3.6 \mathrm{~m} / \mathrm{s}$ and;

4 Four wind angle of incidence of $0.0,30,60$ and $90^{\circ}$.

\section{INSTRUMENTS AND MEASUREMENT:}

A Japanese type thermal anemometer (model: 24-6111) was used for measuring the wind velocity and local wind pressure. For air velocity, the device has a range from 0.0 to $50 \mathrm{~m} / \mathrm{s}$ with precision of $0.1 \mathrm{~m} / \mathrm{s}$. Also, the anemometer has a rang of pressure from 0.0 to $500 \mathrm{~mm}\left(\mathrm{H}_{2} \mathrm{O}\right)$ with the precision of $0.1 \mathrm{~mm}$. Pitot-tube and manometer sensor were used for measuring the static pressure.

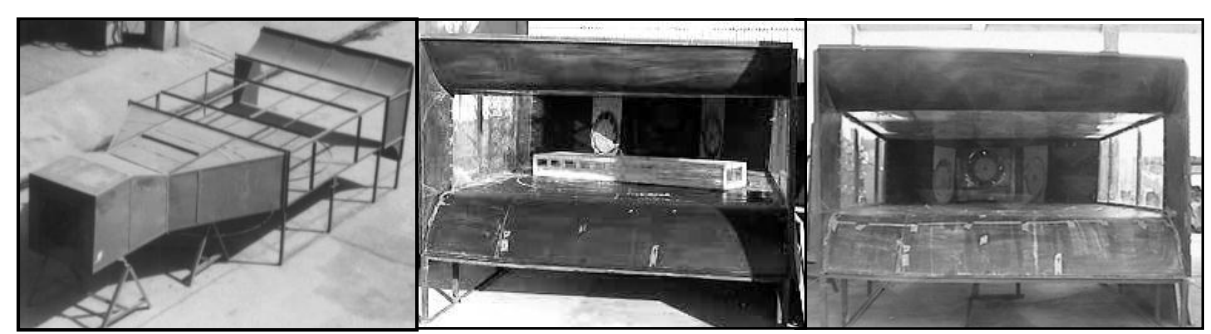

Fig. 3: Wind tunnel photographs.

\section{METHODS:}

\section{Wind pressure coefficient:}

The wind pressure coefficient around each window is defined as (ASHRAE, 1989): 


$$
C p=\frac{\left(p-p_{r e f}\right)}{1 / 2 \rho V_{r e f}^{2}} .
$$

Where:

$C p \quad$ wind pressure coefficient, dimensionless;

$P \quad$ wind pressure around each window, $\mathrm{Pa}$;

$P_{\text {ref }} \quad$ reference static pressures in the undisturbed flow, $\mathrm{Pa}$;

$\rho$ density of the air, $\mathrm{kg} / \mathrm{m}^{3}$; and

$V_{\text {ref }}$ reference wind velocity of free stream of wind, $\mathrm{m} / \mathrm{s}$.

\section{Airflow rate:}

The flow rate of wind through the windows is calculated using the following relationship (ASHRAE,1989 and Albright 1990):

$$
Q_{a}=C d \cdot A \cdot \frac{\left(C p_{W-L}-C p_{i}\right)}{\sqrt{\left|C p_{W-L}-C p_{i}\right|}} \cdot V_{r e f}
$$

Where:

$Q_{a} \quad$ actual airflow rate through windows, $\mathrm{m}^{3} / \mathrm{s}$;

$C d \quad$ discharge coefficient of the window (0.6, dimensionless);

A free surface area of the windows, $\mathrm{m}^{2}$;

$C p_{W-L}$ mean external wind pressure coefficient around the windows "i.e. windward or leeward sides of the model", dimensionless;

$C p_{i}$ internal wind pressure coefficient "inside the model", dimensionless; and

$V_{\text {ref }}$ reference wind velocity of free stream of wind; $\mathrm{m} / \mathrm{s}$.

The sign $\left(C p_{W-L}-C p_{i}\right)$ reflects the direction of the airflow through window $\mathrm{j}$ : a positive sign refers to inflow, a negative sign refers to outflow.

According to the continuity equation, stating that all inflowing air through the inlets has to leave through the outlet windows, one can write for $\mathrm{n}$ windows:

$$
\sum_{j}^{n} Q_{a}=0.0
$$

The flow rate of wind through the windows for model-A is calculated using the following relationship: 
$Q_{a}=C d \cdot A_{\text {sidewall }} \cdot \frac{\left(C p_{W}-C p_{i}\right)}{\sqrt{\left|C p_{W}-C p_{i}\right|}} \cdot V_{\text {ref }}+C d \cdot A_{\text {sidewall }} \cdot \frac{\left(C p_{L}-C p_{i}\right)}{\sqrt{\left|C p_{L}-C p_{i}\right|}} \cdot V_{r e f}=0.0$

or

$Q_{a}=C d \cdot A_{\text {sidewall }} \cdot V_{\text {ref }}\left[\frac{\left(C p_{W}-C p_{i}\right)}{\sqrt{\left|C p_{W}-C p_{i}\right|}}+\frac{\left(C p_{L}-C p_{i}\right)}{\sqrt{\left|C p_{L}-C p_{i}\right|}}\right]=0.0$

Where:

$Q_{a} \quad$ actual airflow rate through windows, $\mathrm{m}^{3} / \mathrm{s}$;

$C d \quad$ discharge coefficient of the window, dimensionless;

$A_{\text {sidewall }}$ free surface area of the windows at the sidewall, $\mathrm{m}^{2}$;

$C p_{W}$ mean external wind pressure coefficient around the windward windows, dimensionless;

$C p_{L}$ mean external wind pressure coefficient around the leeward windows, dimensionless;

$C p_{i}$ internal wind pressure coefficient "inside the model", dimensionless; and

$V_{\text {ref }}$ reference wind velocity of free stream of wind, $\mathrm{m} / \mathrm{s}$.

For model-B, the flow rate of wind through the windows is calculated using the following relationship:

$$
\begin{aligned}
& Q_{a}=C d . A_{\text {sidewall }} \cdot V_{\text {ref }}\left[\frac{\left(C p_{W}-C p_{i}\right)}{\sqrt{\left|C p_{W}-C p_{i}\right|}}+\frac{\left(C p_{L}-C p_{i}\right)}{\sqrt{\left|C p_{L}-C p_{i}\right|}}\right]+C d . A_{\text {endwall }} \cdot V_{\text {ref }} \text {. } \\
& {\left[\frac{\left(C p_{e}-C p_{i}\right)}{\sqrt{\left|C p_{e}-C p_{i}\right|}}+\frac{\left(C p_{e}-C p_{i}\right)}{\sqrt{\left|C p_{e}-C p_{i}\right|}}\right]=0.0}
\end{aligned}
$$

Where:

$Q_{a} \quad$ actual airflow rate through windows, $\mathrm{m}^{3} / \mathrm{s}$;

$\mathrm{Cd}$ discharge coefficient of the window, dimensionless;

$A_{\text {sidewall }}$ free surface area of the windows at the sidewall, $\mathrm{m}^{2}$;

$A_{\text {endwal }}$ free surface area of the windows at the endwall, $\mathrm{m}^{2}$;

$C p_{W}$ mean external wind pressure coefficient around the windward windows, dimensionless; 
$C p_{L} \quad$ mean external wind pressure coefficient around the leeward windows, dimensionless;

$C p_{e}$ mean external wind pressure coefficient around the endwall windows, dimensionless;

$C p_{i} \quad$ internal wind pressure coefficient, dimensionless; and

$V_{\text {ref }}$ reference wind velocity of free stream of wind, $\mathrm{m} / \mathrm{s}$.

For calculating internal wind pressure coefficient $\left(C p_{i}\right)$, the iteration methodology was followed manually.

\section{Ventilation coefficient:}

The ventilation coefficient of all inlet windows is defined as (ASHRAE, 1989 and Albright 1990):

$$
C_{v}=\frac{Q_{a}}{A_{\text {inlet }} \cdot V_{\text {ref }}}
$$

Where:

$C_{v} \quad$ ventilation coefficient, dimensionless;

$Q_{a} \quad$ actual airflow rate through windows, $\mathrm{m}^{3} / \mathrm{s}$;

$A_{\text {inlet }}$ free surface area of the inlet windows, $\mathrm{m}^{2}$; and

$V_{\text {ref }}$ reference wind velocity of free stream of air, $\mathrm{m} / \mathrm{s}$.

\section{Reynolds number:}

According to Timmons, 1984 airflow patterns will remain constant above a certain threshold Reynolds number $\left(2 \times 10^{4}\right)$. Reynolds analogy provides the dynamic similarity for a geometric scale model. The Reynolds number is the ratio of the inertia to viscous forces in a fluid stream. For flow configurations in the test section, the Reynolds number is defined as:

$$
R_{e}=\frac{V_{r e f} \cdot L}{v}
$$

Where:

$R_{e} \quad$ Reynolds number, dimensionless;

$V_{\text {ref }} \quad$ reference velocity in the test section, $\mathrm{m} / \mathrm{s}$;

$L \quad$ reference dimension of the model, $\mathrm{m}$; and

$v \quad$ kinematic viscosity of air $\left(1.46 \times 10^{-5} \mathrm{~m}^{2} / \mathrm{s}\right.$, according to Douglas et al., 1990). 


\section{Flow visualization:}

Airflow patterns were visualized using mineral oil burning smoke unit (smoke tracers). To assess the movement of wind through the windows of the mode, the smoke generator was operated to completely fill the testsection wind tunnel and the smoke movements in and out of model windows were visually observed and recorded by using a video unit. Similarly to observe and record the smoke movement out of the model windows, the smoke generator used to fill-in the model only and smoke outlet through the window was also visually recorded using the video unit. The obtained smoke flow patterns were later analyzed to introduce a visible visualization of air inlet and outlet zones.

\section{RESULTS AND DISCUSSION}

The performance criteria in the following sections are the values of wind pressure coefficient around the models, ventilation coefficient and ventilation rate. Graphical and visible visualization of inlet and outlet zones on the different walls of each model were introduced as well.

\section{Wind pressure coefficient $(C p)$ :}

Figs. 4 to 13 illustrate the values of wind pressure coefficient for models $\mathrm{A}$ and $\mathrm{B}$ as affected by wind angle of incidence and wind velocity. Values of wind pressure coefficient are indicated on a schematic plan view of the physical models. Each value in the Figures represents the wind pressure coefficient at a window. The perpendicular line at each window is proportional to the value of $C p$ for that window. A breaking line was drawn to connect the ends of these perpendicular lines in order to show the variation in $C p$ along each wall. Positive values of $C p$ were drawn inside the plan view and the negative values were drawn outside it. So that, the Figures can be considered as airflow diagrams for models A and $\mathrm{B}$.

At wind angle of $90^{\circ}$ and wind velocities of 2.5 and 3.6m/s, Figs. 4, 5, 6 and 10 illustrate that, all values of wind pressure coefficients on the windward wall $\left(C p_{W}\right)$ were positive and the maximum values were observed close to end walls at windows number (1) and (12) for models $\mathrm{A}$ and $\mathrm{B}$. 


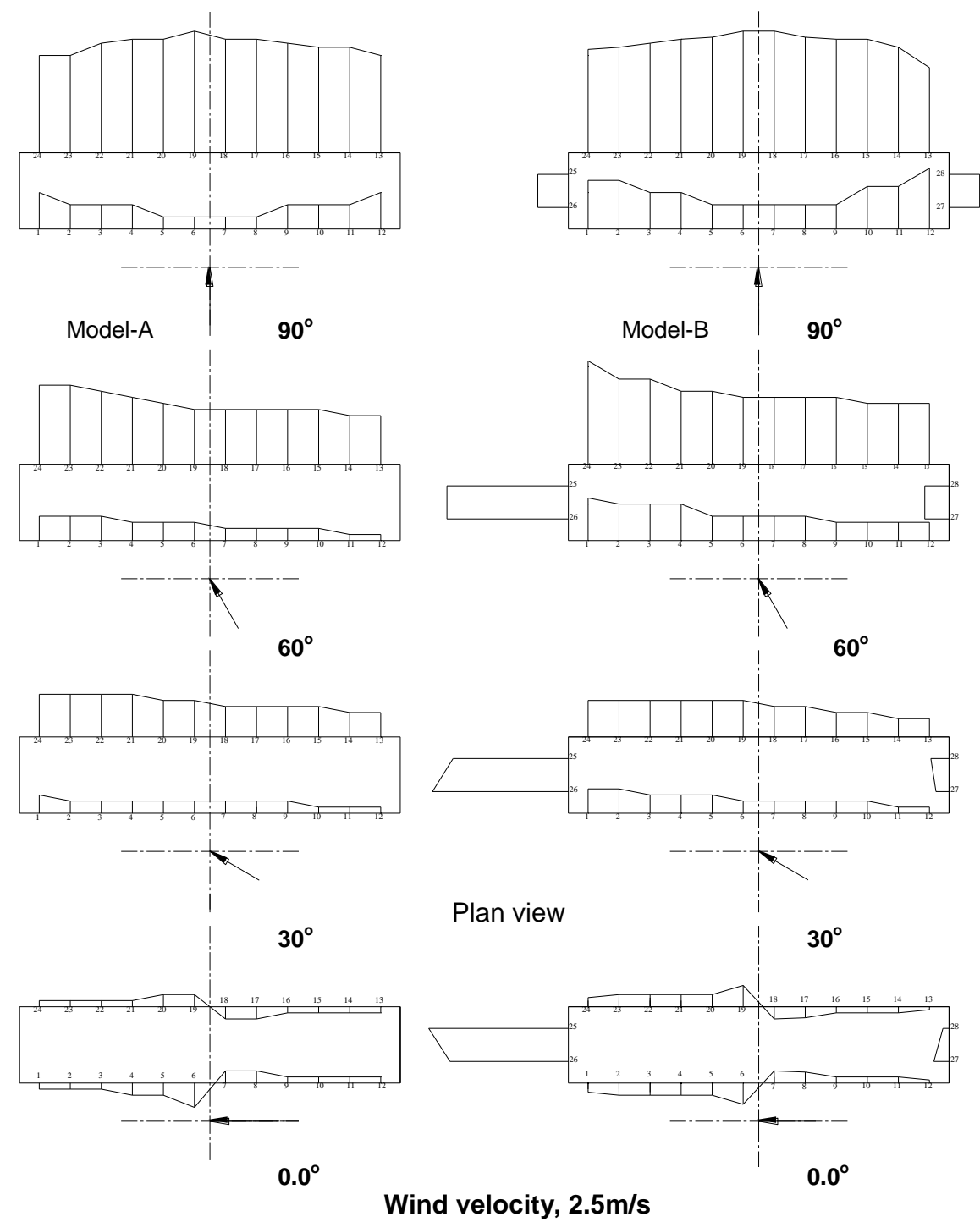

Fig. 4: Wind pressure coefficients for models $A$ and $B$ at $2.5 \mathrm{~m} / \mathrm{s}$ wind velocity as affected by different wind angle.

On the other hand, all the values of wind pressure coefficients on the leeward wall $\left(C p_{L}\right)$ were found to be negative and the maximum negative values were found far from end walls at windows number (18) and (19) at the same previous models. 

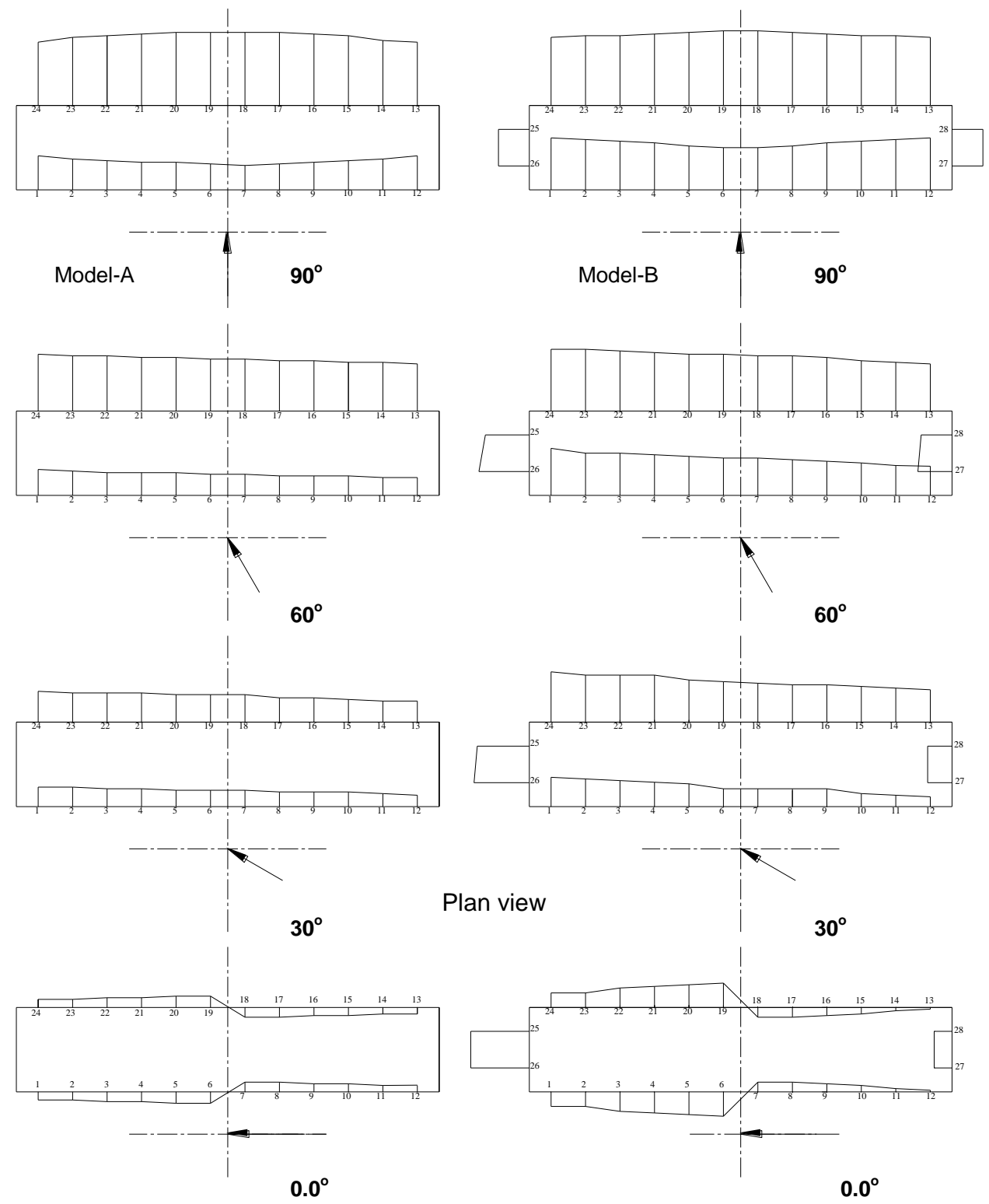

Wind velocity, $3.6 \mathrm{~m} / \mathrm{s}$

Fig. 5: Wind pressure coefficients for models $A$ and $B$ at $3.6 \mathrm{~m} / \mathrm{s}$ wind velocity as affected by different wind angle. 

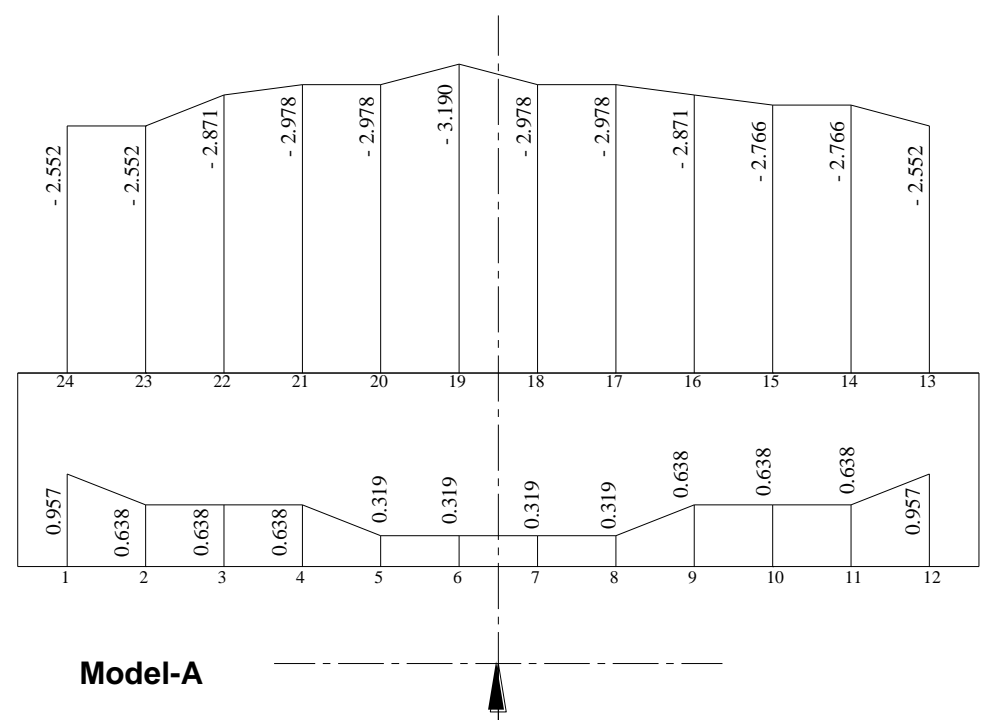

Wind angle, $90^{\circ}$

Wind velocity, $2.5 \mathrm{~m} / \mathrm{s}$

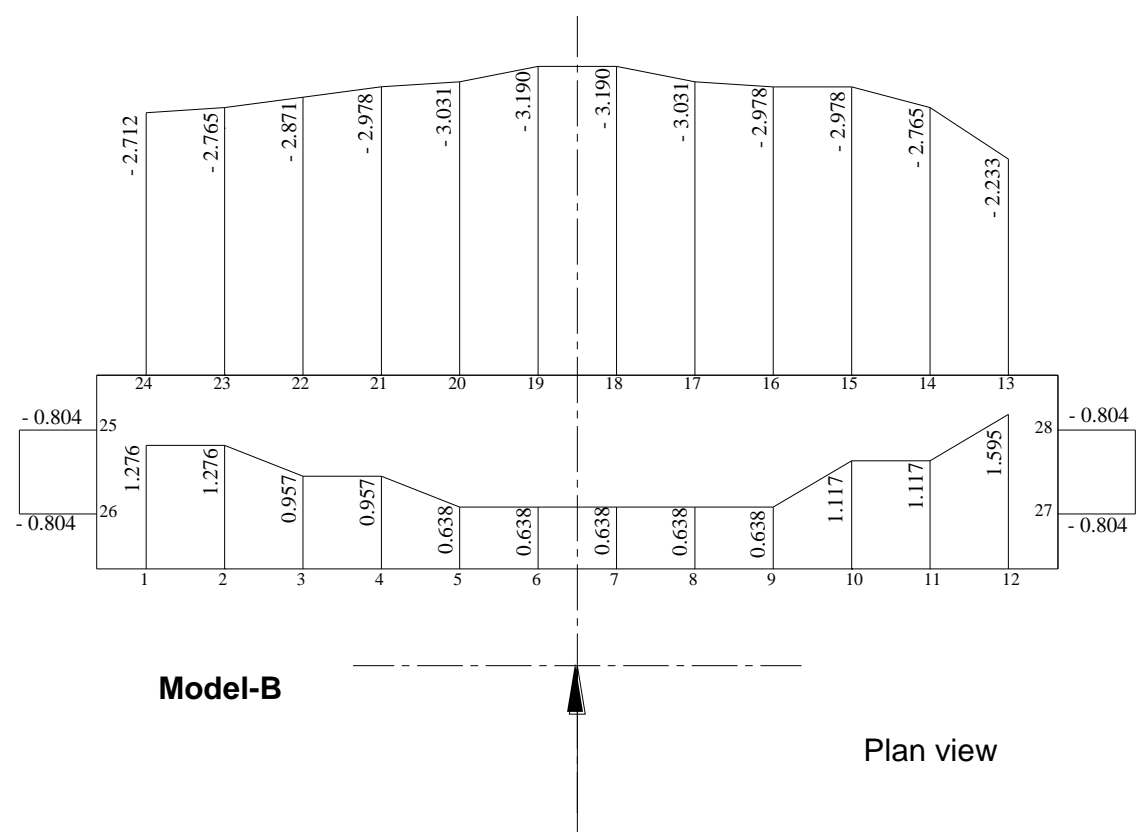

Fig. 6: Wind pressure coefficient for models $A$ and $B$ at $90^{\circ}$ wind angle and $2.5 \mathrm{~m} / \mathrm{s}$ wind velocity. 


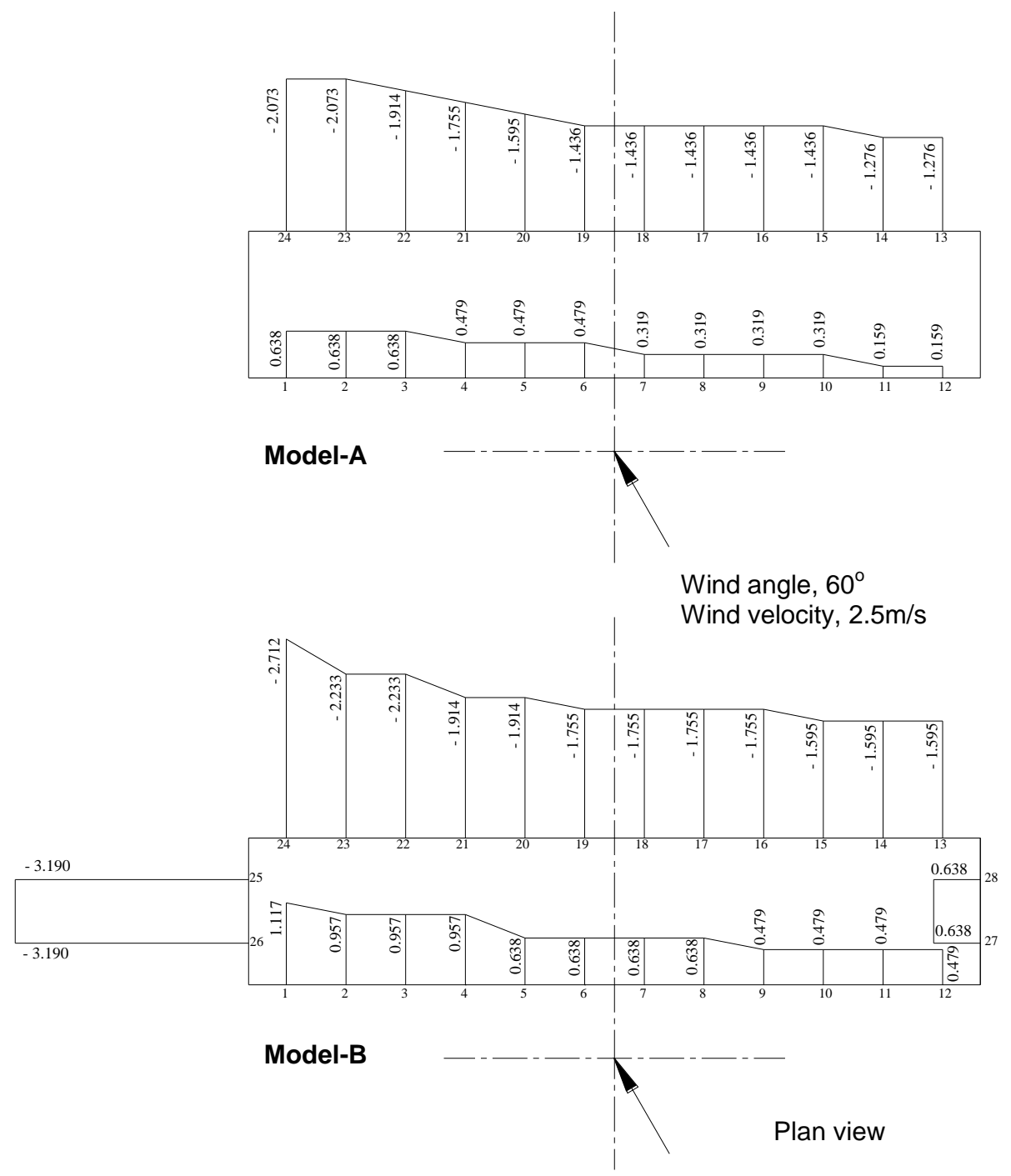

Fig. 7: Wind pressure coefficient for models $A$ and $B$ at $60^{\circ}$ wind angle and $2.5 \mathrm{~m} / \mathrm{s}$ wind velocity.

Also, the values of wind pressure coefficient on both endwalls $\left(C p_{e}\right)$ were negative at each of two windows on both endwalls for model-B. For instance and concerning model-B, the maximum values of $C p_{W}$ were 1.276 and 1.595 on windows number (1) and (12) at wind velocity of $2.5 \mathrm{~m} / \mathrm{s}$, respectively. 


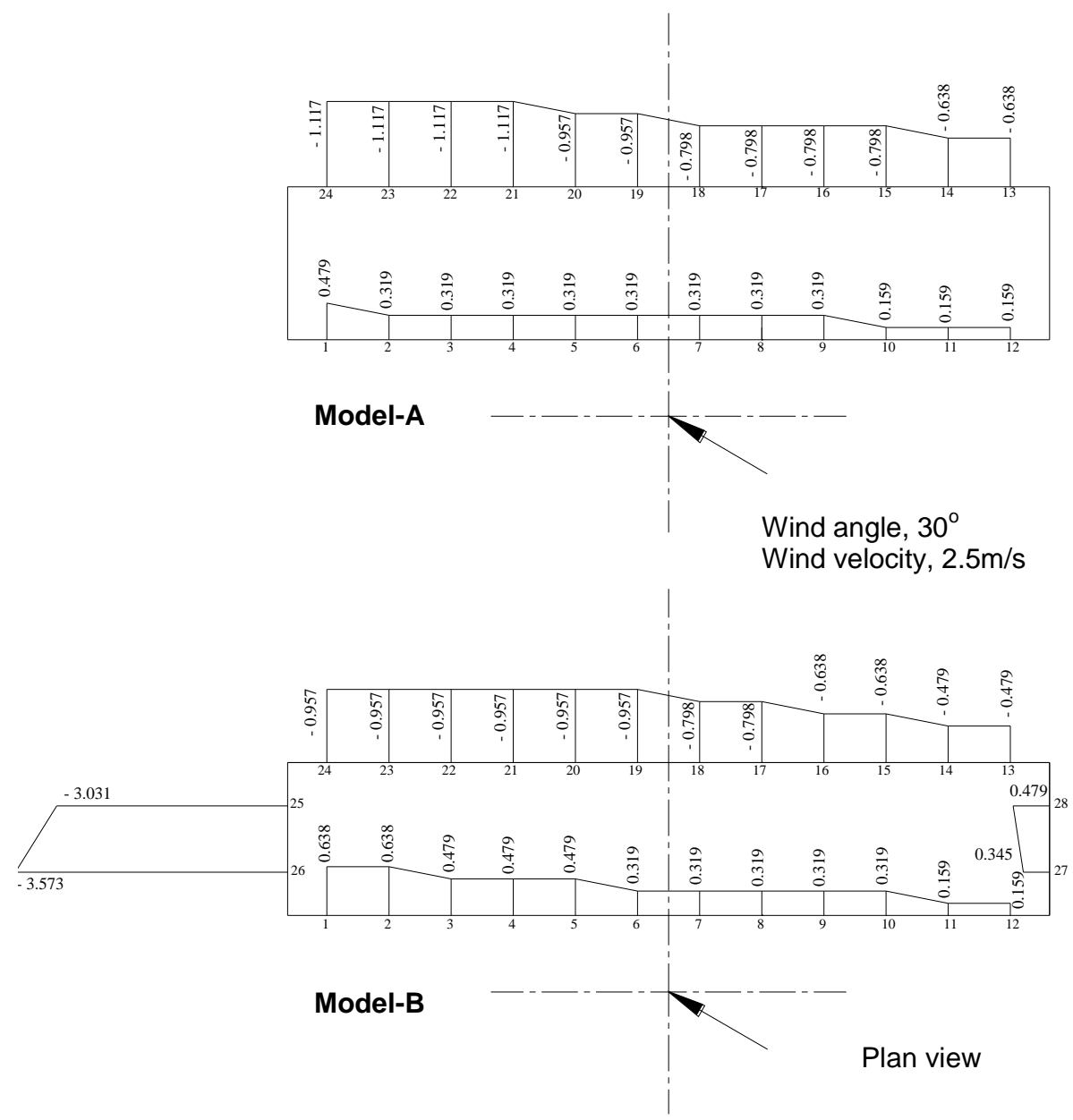

Fig. 8: Wind pressure coefficient for models $A$ and $B$ at $30^{\circ}$ wind angle and $2.5 \mathrm{~m} / \mathrm{s}$ wind velocity.

While, at wind velocity of $3.6 \mathrm{~m} / \mathrm{s}$ the corresponding values have the same value of 1.231. On another side, the maximum negative values of $C p_{L}$ were found to have the same value at windows number (18) and (19) and they were -3.190 and -1.769 at wind velocities of 2.5 and $3.6 \mathrm{~m} / \mathrm{s}$, respectively. Also, the values of $C p_{e}$ were -0.804 and -0.731 at 2.5 and $3.6 \mathrm{~m} / \mathrm{s}$ wind velocities respectively.

At wind angles of 60 and $30^{\circ}$ and different wind velocities of 2.5 and $3.6 \mathrm{~m} / \mathrm{s}$, Figs. 4, 5, 7, 8, 11 and 12, show that, the values of wind pressure coefficients on the windward wall $\left(C p_{W}\right)$ were positive for all windows. It 
increased gradually by increasing the distance from the closest end to wind entrance. Maximum value of wind pressure coefficient on the windward wall was recorded at window number (1) for models A and B. On the other hand, the values of wind pressure coefficients on the leeward wall $\left(C p_{L}\right)$ were negative for all windows and were also gradually increased in the same direction as $C p_{W}$ for the same previous models. Relating to model-B, values of wind pressure coefficient $\left(C p_{e f}\right)$ for the front endwall the were positive. Whilst, the values of wind pressure coefficient for the rear endwall $\left(C p_{e r}\right)$ were negative and the maximum negative ones were recorded at window number (26).

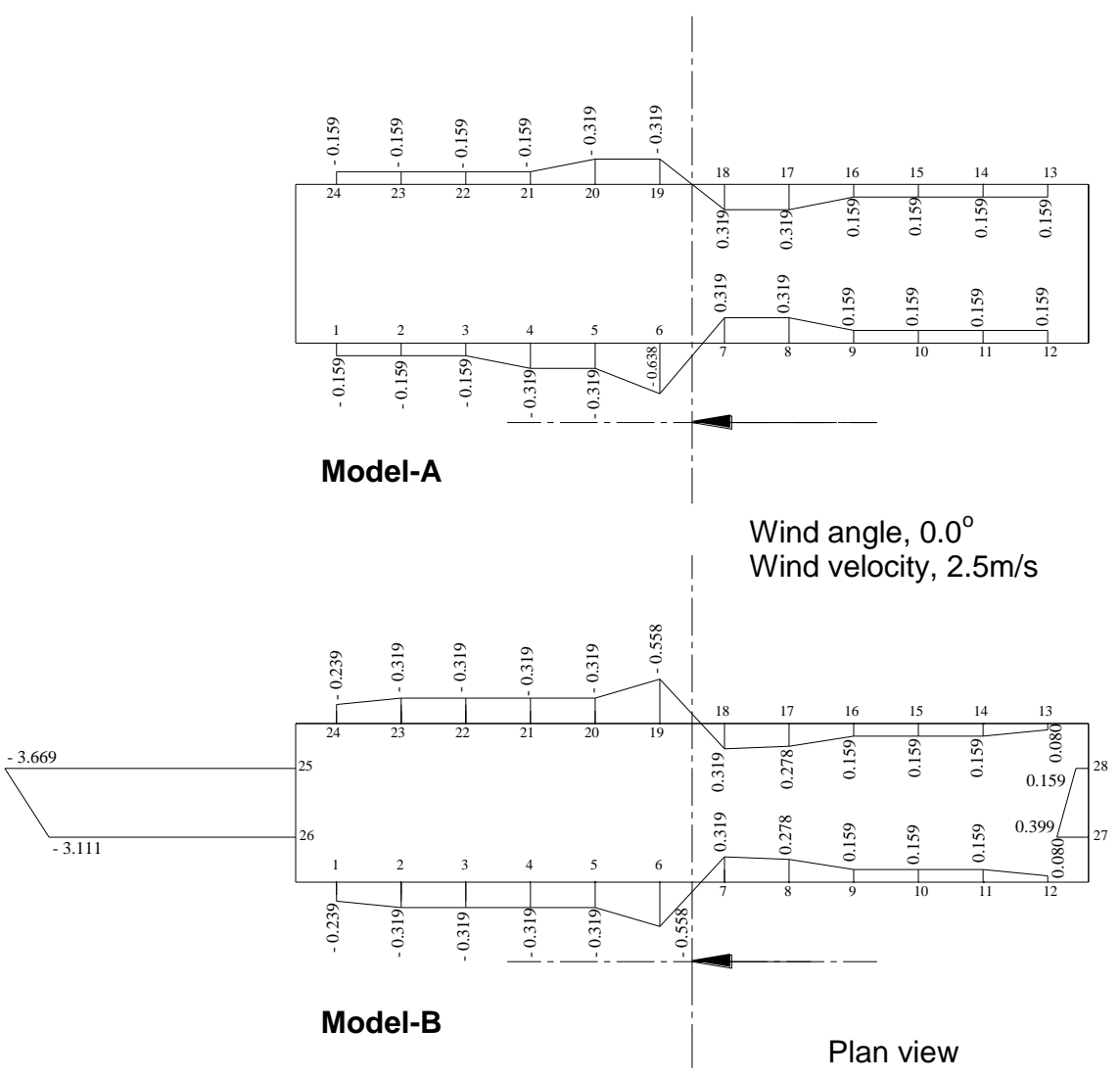

Fig. 9: Wind pressure coefficient for models $A$ and $B$ at $0.0^{\circ}$ wind angle and $2.5 \mathrm{~m} / \mathrm{s}$ wind velocity. 

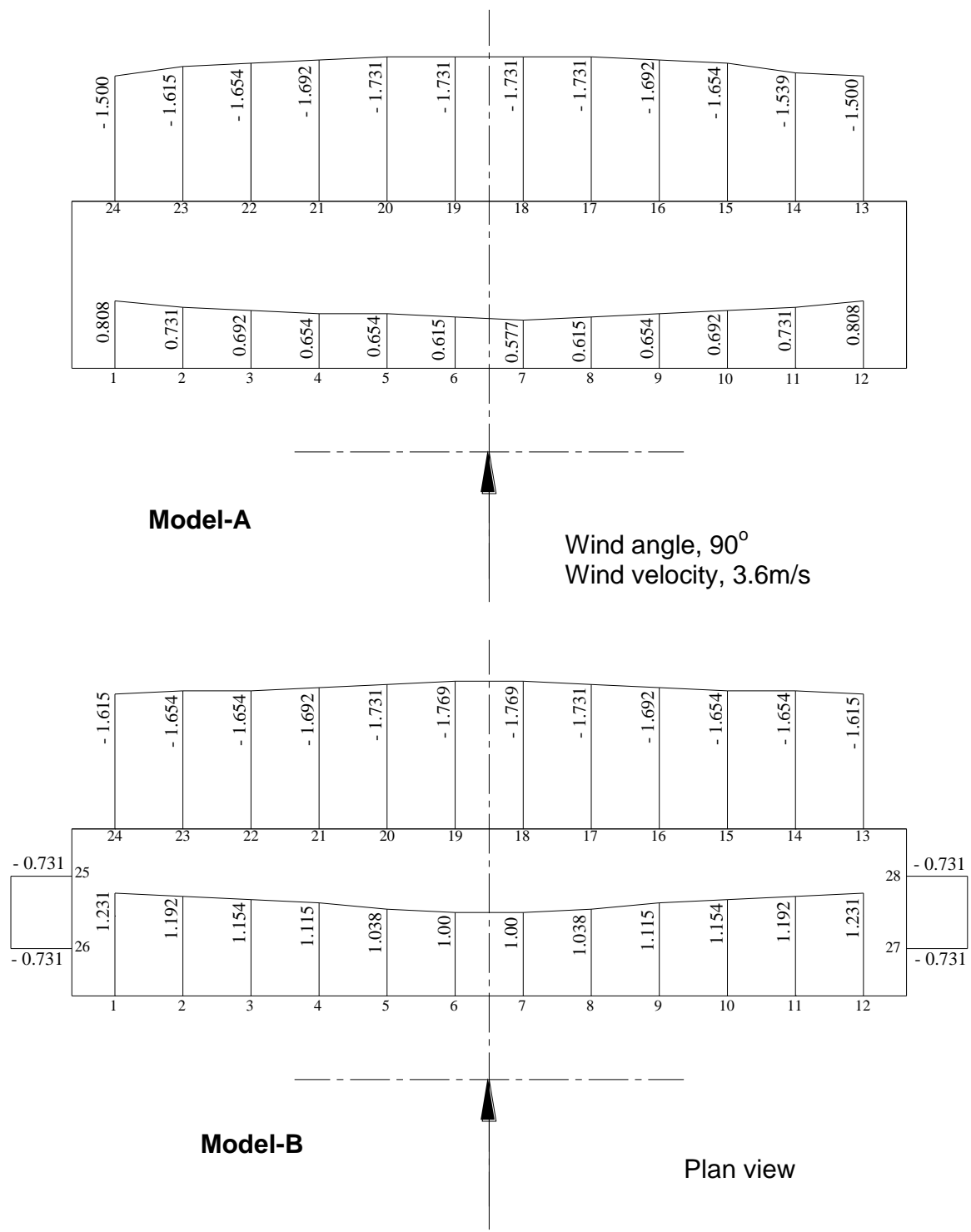

Fig. 10: Wind pressure coefficient for models $A$ and $B$ at $90^{\circ}$ wind angle and $3.6 \mathrm{~m} / \mathrm{s}$ wind velocity.

Concerning model-A, Figs. 4, 5, 9 and 13 illustrate that, wind pressure coefficient values on the closest half of both sidewalls to wind entrance were positive as indicated for windows from 7 to 18 at zero wind angle and wind velocities of 2.5 and $3.6 \mathrm{~m} / \mathrm{s}$. While the wind pressure coefficient values on the other half of both sidewalls were negative as 
indicated for windows from 1 to 6 and from 19 to 24 at the same previous conditions. Relating to model-B, zero wind angle and wind velocities of 2.5 and $3.6 \mathrm{~m} / \mathrm{s}$,

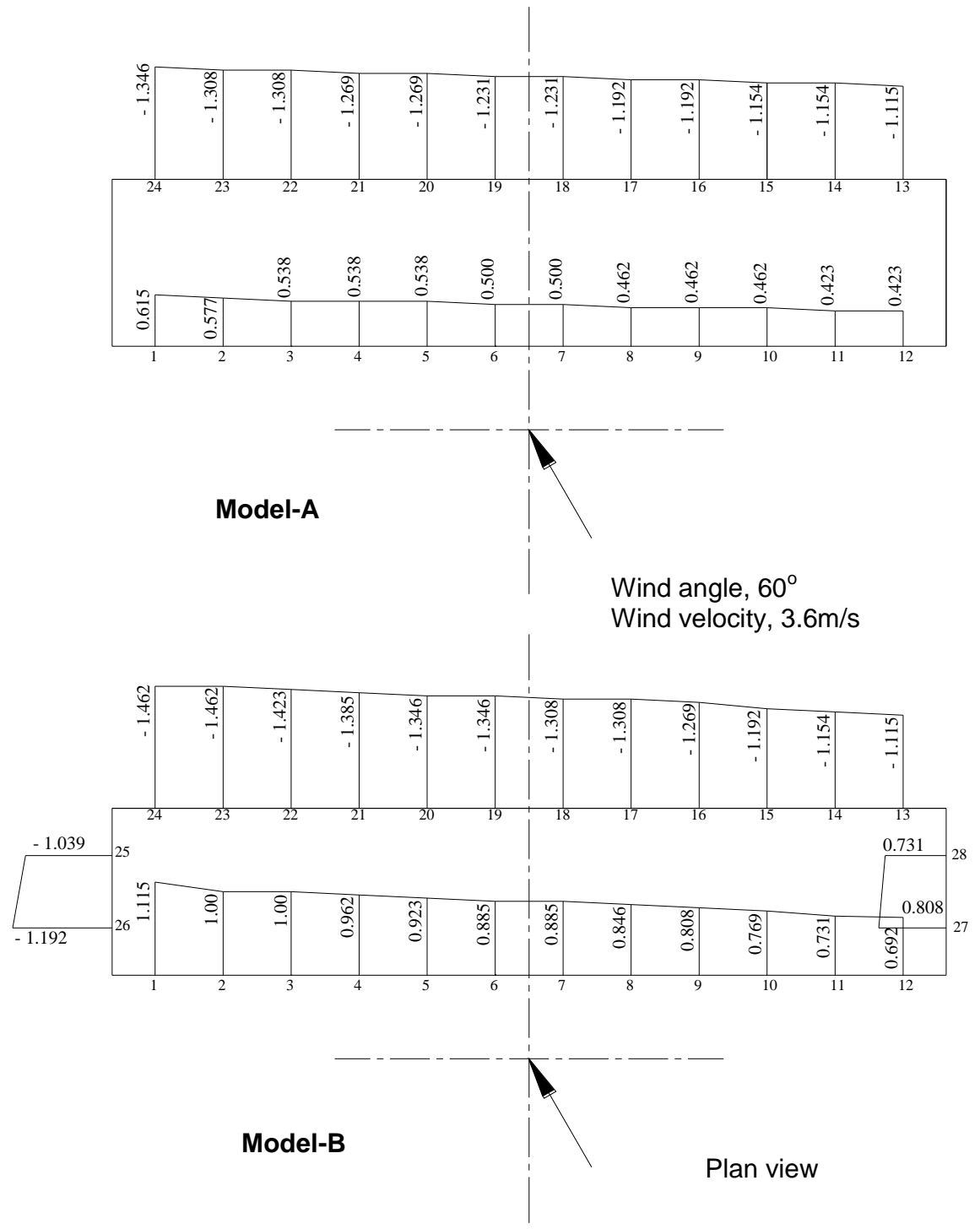

Fig. 11: Wind pressure coefficient for models $A$ and $B$ at $60^{\circ}$ wind angle and $3.6 \mathrm{~m} / \mathrm{s}$ wind velocity.

Figs. 4, 5, 9 and 13 show that, wind pressure coefficient values on the half of both sidewalls nearest to wind entrance and on the front endwall 
were positive as indicated for windows from 7 to 18,27 and 28. On the other hand, wind pressure coefficient values on the other half of both sidewalls farthest from window the rear endwall were negative as indicated for windows from 1 to 6 from 19 to 24,25 and 26.

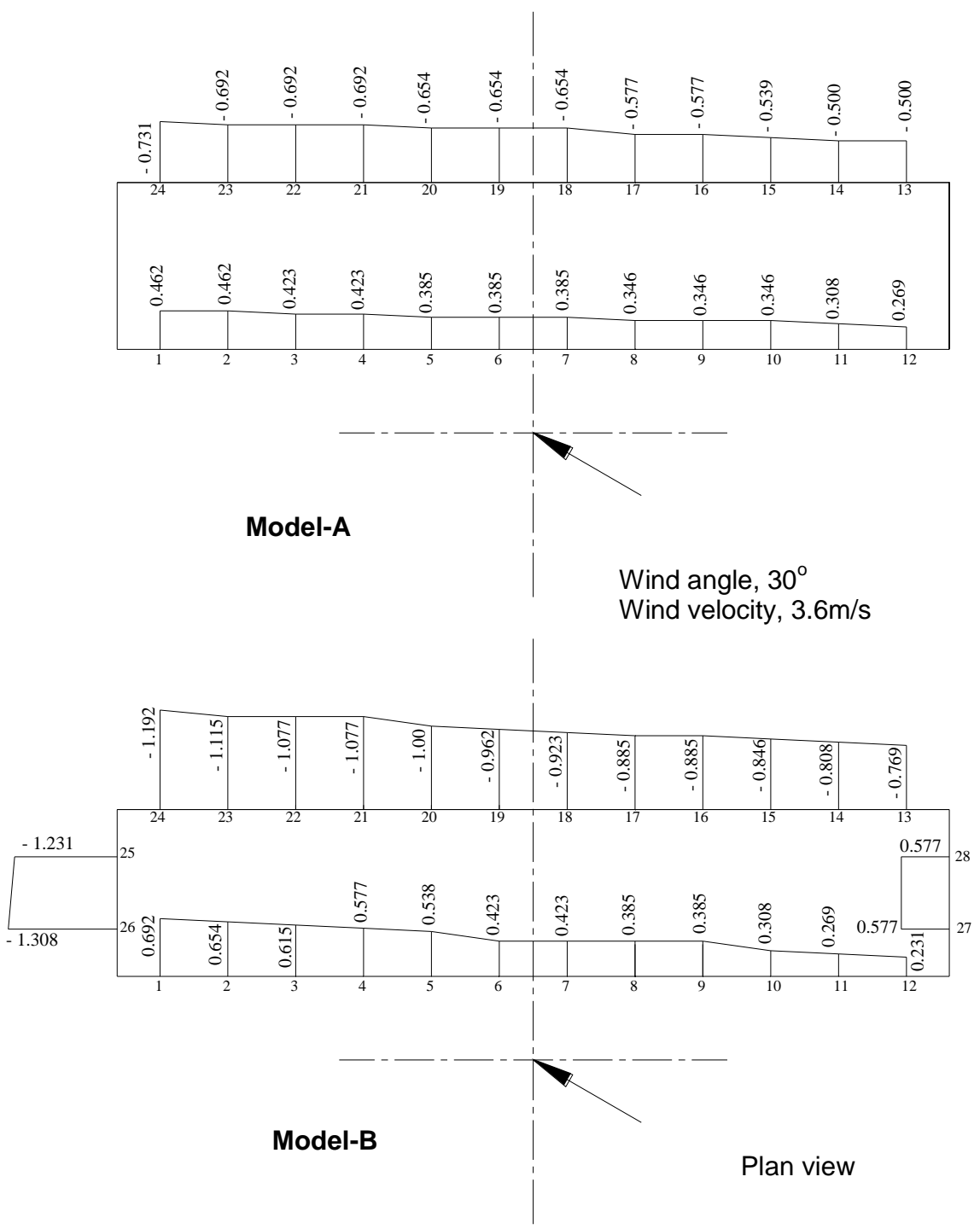

Fig. 12: Wind pressure coefficient for models $A$ and $B$ at $30^{\circ}$ wind angle and $3.6 \mathrm{~m} / \mathrm{s}$ wind velocity. 


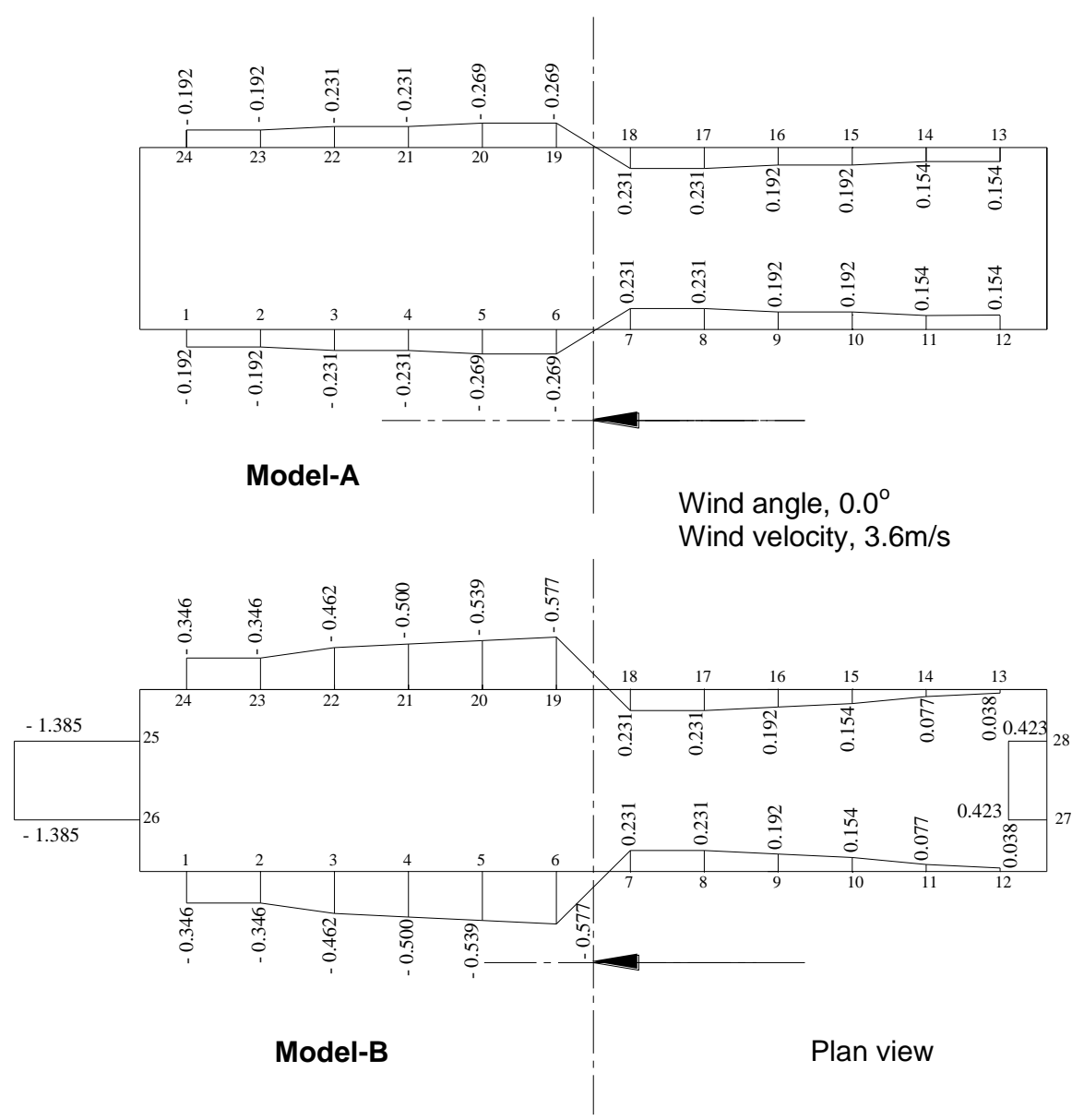

Fig. 13: Wind pressure coefficient for models $A$ and $B$ at $0.0^{\circ}$ wind angle and $3.6 \mathrm{~m} / \mathrm{s}$ wind velocity.

It was revealed that the wooden frame of the physical model and the existence of wind wall windows occurred an effect on this behavior.

Comparing the mean values of wind pressure coefficient for models $\mathrm{A}$ and $\mathrm{B}$, by increasing wind angles from 30 to $90^{\circ}$ and wind velocity of $2.5 \mathrm{~m} / \mathrm{s}$, It can be conclude that, the mean values of wind pressure coefficient on the windward wall for model-B was higher than that of model-A by percentage ranged from 31.84 to $63.66 \%$, respectively. Also, at the same wind angles and wind velocity of $3.6 \mathrm{~m} / \mathrm{s}$, the mean value of wind pressure coefficient on the windward wall for model-B was higher 
than that of model-A by about from 21.18 to $63.55 \%$, respectively. On the other hand, at wind angle of $0.0^{\circ}$ the mean values of wind pressure coefficient on the windward wall for models $\mathrm{A}$ and $\mathrm{B}$ has not taken a stable trend for two wind velocities under study.

\section{Ventilation coefficient:}

Fig. 14 illustrates the ventilation coefficients for models A and B as affected by wind angle of incidence and wind velocity. The Figure shows that, the highest value of ventilation coefficient was found at wind angle of $90^{\circ}$ and wind velocity of $2.5 \mathrm{~m} / \mathrm{s}$ for model-B. In the same manner, the lowest value was found at wind angle of 0.0 and wind velocity of $3.6 \mathrm{~m} / \mathrm{s}$ for model-A. Comparing the values of ventilation coefficients for models $\mathrm{A}$ and $\mathrm{B}$ at wind angles of $0.0,30,60$ and $90^{\circ}$ and wind velocity of $2.5 \mathrm{~m} / \mathrm{s}$, the results showed that, the values of ventilation coefficient for model-B were higher than that of model-A by about 31.03, 15.22, 13.33 and $2.56 \%$, respectively. While at the same wind angles and wind velocity of $3.6 \mathrm{~m} / \mathrm{s}$, the values of ventilation coefficient for model-B were higher than that of model-A about by $28.89,21.43,14.87$ and $6.73 \%$, respectively.

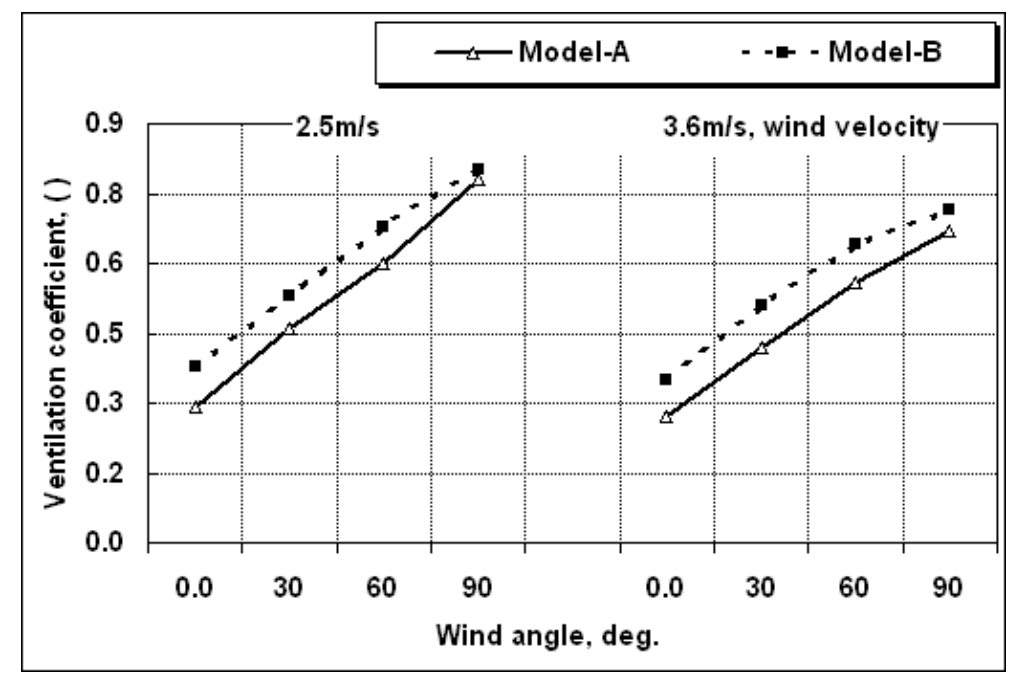

Fig. 14: Ventilation coefficients for models $A$ and $B$ as affected by wind angle and wind velocity. 


\section{Ventilation rate:}

The data presented in Table 1 illustrates the values of ventilation rate for models $\mathrm{A}$ and $\mathrm{B}$ as affected by wind angle of incidence and wind velocity. The results indicated that the highest value of ventilation rate was found at wind angle of $60^{\circ}$ and wind velocity of $3.6 \mathrm{~m} / \mathrm{s}$ for model-B. This effect was due to the increasing of the number windows which facing wind force, and results an increasing in ventilation area of this model. In contrary, the lowest value of ventilation rate by using model-A, wind angle of $0.0^{\circ}$ and wind velocity of $2.5 \mathrm{~m} / \mathrm{s}$. The results also showed that, the values of ventilation rate at wind angles of $0.0,30,60$, and $90^{\circ}$ and wind velocity of $2.5 \mathrm{~m} / \mathrm{s}$, were higher for model-B than model-A by about 56.99, 34.10, 32.41 and $1.29 \%$, respectively. Whilst at the same wind angles and wind velocity of $3.6 \mathrm{~m} / \mathrm{s}$, the corresponding values of ventilation rates for model-B were higher than that of model-A by about $50.85,42.02,34.13$ and $6.82 \%$, respectively.

Table 1:Ventilation rate for models $A$ and $B$ as affected by wind angle of incidence and wind velocity.

\begin{tabular}{|c|c|c|c|c|}
\hline \multirow{2}{*}{$\begin{array}{c}\text { Wind angle, } \\
\text { deg. }\end{array}$} & \multicolumn{4}{|c|}{ Ventilation rate, $\mathbf{~ m}^{\mathbf{3}} / \mathbf{s}$} \\
\cline { 2 - 5 } $\mathbf{2 . 5 m} / \mathbf{s}$ & Model-B & Model-A & Model-B \\
\hline $\mathbf{0 . 0}$ & Model-A & 0.08870 & 0.07690 & 0.1160 \\
\hline $\mathbf{3 0}$ & 0.05650 & 0.12270 & 0.11970 & 0.1700 \\
\hline $\mathbf{6 0}$ & 0.11880 & 0.15730 & 0.15910 & 0.2134 \\
\hline $\mathbf{9 0}$ & 0.15560 & 0.15760 & 0.19070 & 0.2037 \\
\hline
\end{tabular}

\section{Flow visualization:}

Comparative study between the two tested physical models A and B, showed that, model-B was found to be the most adequate for uniformity the airflow shape. This effect was due to the increasing of the number windows which results in increasing ventilation area of this model. Fig. 15 illustrates the airflow shape of model-B as affected by $0.0,60$ and $90^{\circ}$ wind angle of incidence and $3.6 \mathrm{~m} / \mathrm{s}$ wind velocity.

From the present study it can conclude that, the simulation study of the wind-induced natural ventilation through the physical modelling of a broiler house inside a wind tunnel however it can answer numerous questions that are difficult to be investigated in the field. Finally the designer and operator of the broiler house owned through this study the principle engineering knowledge about the relationship between the wind condition (velocity and direction) and the characteristics of broiler houses 
(regarding windows area and configuration). Since the knowledge of ventilation type and rates is the first step in designing and construction an environmental control system for broiler houses, such knowledge was so needed. Therefore, such knowledge in the present study will contribute in enhancing the available ones to whom concern with environmental control systems, specifically, in such systems working under natural ventilation.

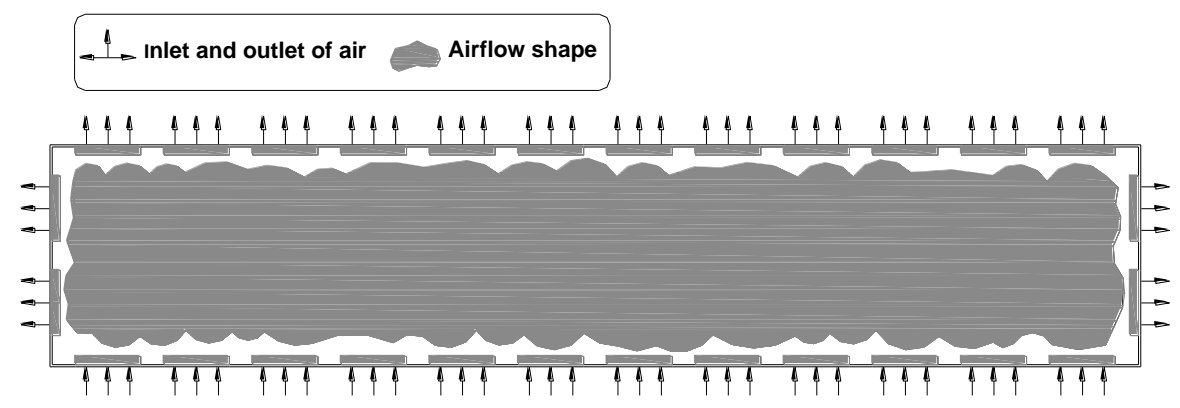

Wind angle, $90^{\circ}$

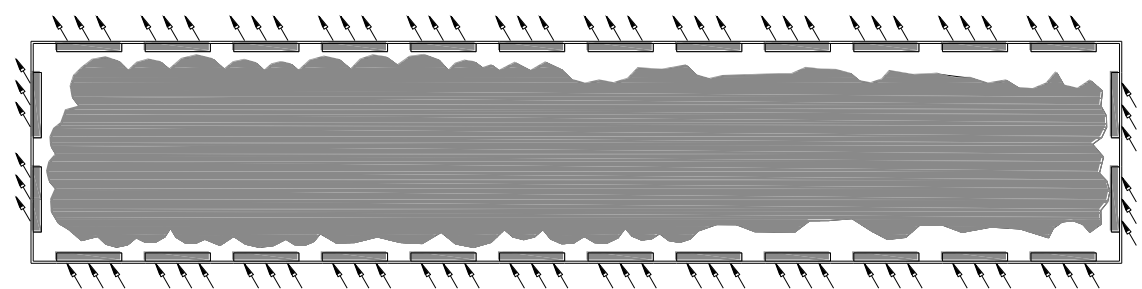

Wind angle, $60^{\circ}$

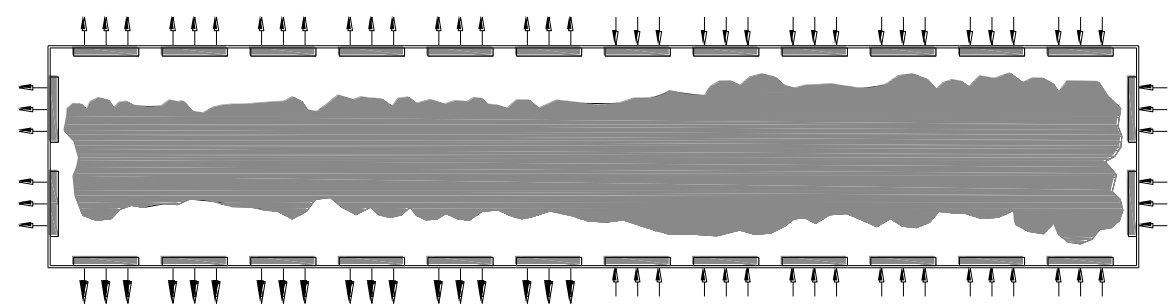

Wind angle, $0.0^{\circ}$

Plan view

Fig. 15: Airflow shape of model-B at $3.6 \mathrm{~m} / \mathrm{s}$ wind velocity as affected by different wind angle. 


\section{CONCLUSION}

Model-B broiler house with windows at the endwalls has the highest values of airflow rate compared to model-A without windows at the endwalls. While, the highest values of ventilation coefficient for the two models A and B were obtained at wind angle of $90^{\circ}$ and $2.5 \mathrm{~m} / \mathrm{s}$ wind velocity. Whereas, the highest mean values of wind pressure coefficients on windward wall for models $\mathrm{A}$ and $\mathrm{B}$ were obtained at wind angle of $90^{\circ}$ and wind velocity of $3.6 \mathrm{~m} / \mathrm{s}$. While, the mean value of wind pressure coefficient on the windward wall for model-B was higher than that of model-A by about $63.55 \%$. Generally, model-B was found to be the most adequate for uniformity the airflow shape.

\section{REFERENCES}

Abdel-Ghafar, E. A. M. (1984). Ventilation curves of commercial poultry buildings in northwest coast of Egypt during winter. Agricultural Research Review. 62(5A): 131-145.

Albright, L. D. (1990). Environment control for animals and plants. St Joseph, Mich.: ASAE.

ASHRAE (1989). Handbook of fundamentals. atlanta, ga. 30329: American society of heating, refrigerating and air-conditioning engineers.

Basiouny, M. A. (2005). A study on natural ventilation for poultry houses. Wind induced natural ventilation through the physical modelling of a broiler house inside a wind tunnel. Unpubl. Ph. D. thesis. Ag. Mech. Dept, Fac. of Ag., Kafr El-Sheikh, Tanta Univ., Egypt.

Blanes-Vidal, V.; V. Fitas and A. Torres (2007) Differential pressure as a control parameter for ventilation in poultry houses: effect on air velocity in the zone occupied by animals, Spanish J. of Ag. Res., 5(1): 31-37.

Douglas, J. F.; J. M. Gasiorek and J. A. Swaffield (1990). Fluid mechanics. Second edition. Longman singapore.

Ismail, M. S. (2007). Simulation of natural ventilation on scale model of a livestock house: Determination of airflow pattern in a water table. J. Trop. Ag. and Fd. Sc., 35(2): 341-349. 
Jiang, Y.; D. Alexander; H. Jenkins; R. Arthur and Q. Chen (2003). Natural ventilation in buildings: measurement in a wind tunnel and numerical simulation with large eddy simulation. J. of Wind Eng. and Industrial Aerodynamics, 91(3): 331-353.

Rahman, M. M.; C. M. Chu; S. Kumaresen; F. Y. Yan; P.H. Kim; M. Mashud and M.S. Rahman (2014). Evaluation of the modified chimney performance to replace mechanical ventilation system for livestock housing. www.sciencedirect.com, $10^{\text {th }}$ International Conference on Mechanical Engineering. 245-248.

Timmons, M. B. (1984). Use of physical models to predict the fluid motion in slot-ventilated livestock structures. Trans. of the ASAE, 27: 502-507.

\section{الملخص العربي}

\section{تصور تخطيطي ومرئي لتأثير قوى الرياح لمأوى دجاج اللحم}

\section{*/محمد عبد الحميد بسيونى}

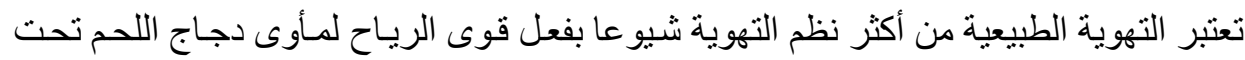

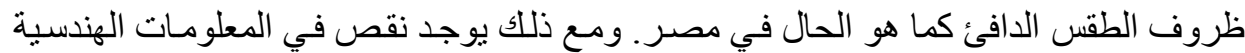

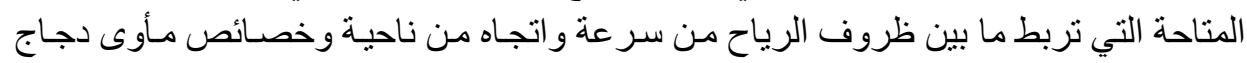

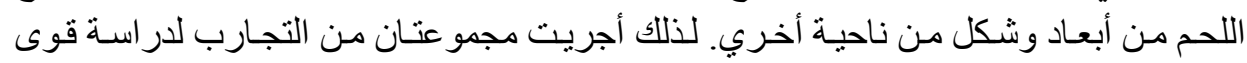

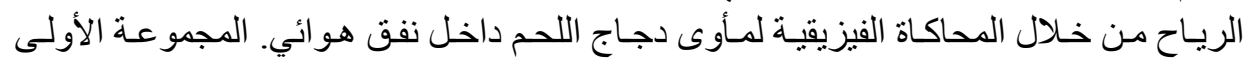

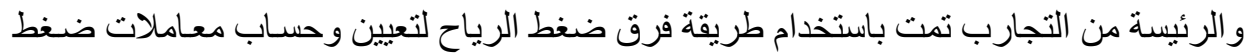

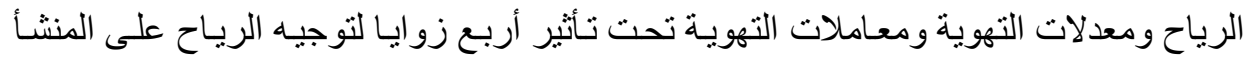

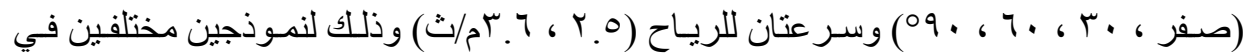

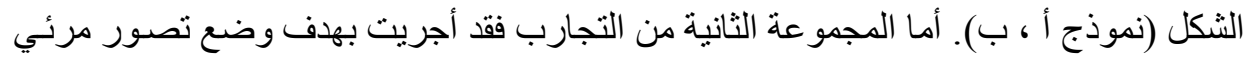

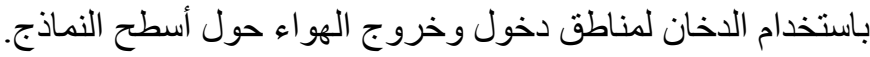

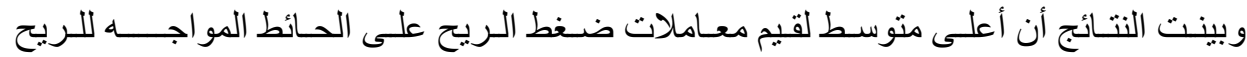

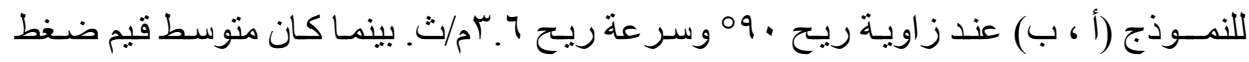

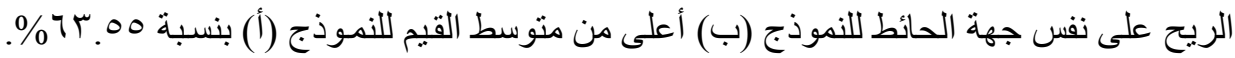

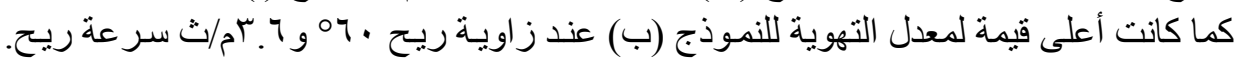

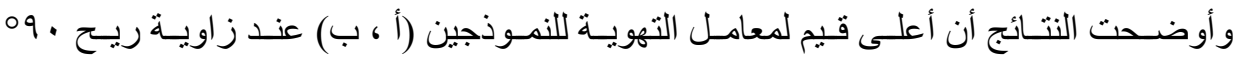

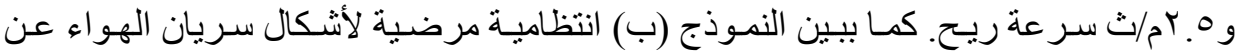
النموذج (أ) تحت ظروف برغ ردج الدر اسة.

* باحث أول بمعهل بحوث الهنلسة الزراعية ـ مركز البحوث الزراعية ـ الجيزة ـ مصر. 